\title{
Rational production of veneer by IR-heating of green wood during peeling: Modeling experiments
}

\author{
Anna Dupleix ${ }^{1, *}$, Sid' Ahmed Ould Ahmedou', \\ Laurent Bleron $^{1}$, Frédéric Rossi ${ }^{1}$ and Mark Hughes ${ }^{2}$ \\ ${ }^{1}$ Arts et Metiers ParisTech LaBoMaP, Rue Porte de Paris, \\ F-71250 Cluny, France \\ ${ }^{2}$ School of Chemical Technology, Department of Forest \\ Products Technology, Aalto University, FI-00076 Aalto, \\ Finland \\ *Corresponding author. \\ Arts et Metiers ParisTech LaBoMaP, Rue Porte de Paris, \\ F-71250 Cluny, France \\ Phone: +33 (0)3 85595327 \\ Fax: +33(0)385595385 \\ E-mail: anna.dupleix@ensam.eu
}

\begin{abstract}
Heating green wood logs by infrared (IR) radiation during peeling for veneer production has been numerically simulated, focusing on the heating kinetics of a green wood cylinder rotating with a decreasing radius. The results confirm those of previous experiments, that this kind of heating is a promising alternative to soaking wood prior to peeling. The model integrates the green wood parameters such as moisture content, density, distribution and ratios of earlywood and latewood, on the one hand, and the peeling conditions of veneer thickness and peeling speed, on the other. The following heat transfer processes were considered: conduction within the bolt, external heating by the IR source, and convection between the bolt surface and the external environment. The outputs were the temperatures of the bolt surface and of layers several millimeters deep. For maximal heat penetration, the bolt should turn in front of the IR source before cutting starts and the IR source should be positioned at the greatest angular distance ahead of the knife. Several heating scenarios could be simulated by the model, thus it is a useful decision-making tool for the design of an in-line IR heating system installed on the peeling lathe.
\end{abstract}

Keywords: green wood; heating; infrared; modeling; peeling for veneer production.

\section{Introduction}

For industrial veneer production, bolts are heated by soaking or steaming prior to peeling, which increases mechanical deformability of wood by softening the lignin moiety (Baldwin 1975; Matsunaga and Minato 1998; Bardet et al. 2003; Yamauchi et al. 2005). Water, as an integral part of wood, makes it an ideal medium for heat transfer into green wood. This kind of pretreatment also reduces the risk of lathe checking, ameliorates veneer surface quality, and lowers cutting forces and power consumption. Thermoforming of wood veneers was discussed by Srinivasan et al. (2007) and the complex interrelation between cutting forces in wood machining was reviewed by Marchal et al. (2009). In the same context, the properties of wood surfaces and the fracture behavior of wood was summarized by Sinn et al. (2009) and Stanzl-Tschegg and Navi (2009), respectively. The mechanical behavior of thin veneers is a special issue, as pointed out recently by Buchelt and Pfriem (2011) and Klüppel and Mai (2012).

The softening of knots contributes to preservation of cutting tool wear (Marchal et al. 2004). Heating alone is also utile, but soaking in water is beneficial because of the improvement of color homogeneity of decorative veneers. However, soaking is an empirical process performed between $32^{\circ} \mathrm{C}$ and $90^{\circ} \mathrm{C}$ (Baldwin 1975) and it has also some disadvantages, for example: (1) the long treatment time (12-72 h); (2) the washing out of extractable matter, which leads to water pollution and affects the natural durability of wood; (3) an increase in bolt-end splitting, which reduces bolt cohesion; and (4) the requirement for large soaking basins and sophisticated handling, i.e., the investment costs are high.

This is the reason why alternative heating solutions are sought for. Experiments with electric ohmic and microwave heating methods (Torgovnikov and Vinden 2010) have demonstrated that the "softening" effect does not depend on heating time, but only on the wood temperature attained, i.e., wood softening does not necessitate "cooking" for a long time as was thought before (Lutz 1960). A promising solution is a local heating of the surface just ahead of the knife, to a depth equal to the thickness of the veneer produced (Marchal and Collet 2000). An IR heating system may be the most suitable technology in terms of rapid heating rates and such a system is easy to install on the peeling lathe (Coste 2005).

Recently, it has been demonstrated that lower bolt surface temperatures of around $50^{\circ} \mathrm{C}$ for beech, birch, Douglas-fir, and spruce, were sufficient for acceptable peeling (Dupleix et al. 2011). It was established that IR radiation is suitable for heating green wood surfaces up to a depth of several millimetres (Gaudilliere 2003). A finite-difference method has demonstrated that living trees are heated via IR radiation (Potter and Andresen 2010). However, the promising experimental results of the quoted authors have not been confirmed by any numerical simulation under conditions of dynamic movement of the $\log$ in terms of IR induced heating rates.

The intention of the present paper is to fill this gap and to model IR heating of logs under industrial conditions of veneer production. The technical feasibility of an in-line IR heating system [Figure 1(a)] is a challenge. The principal issue is the 
a
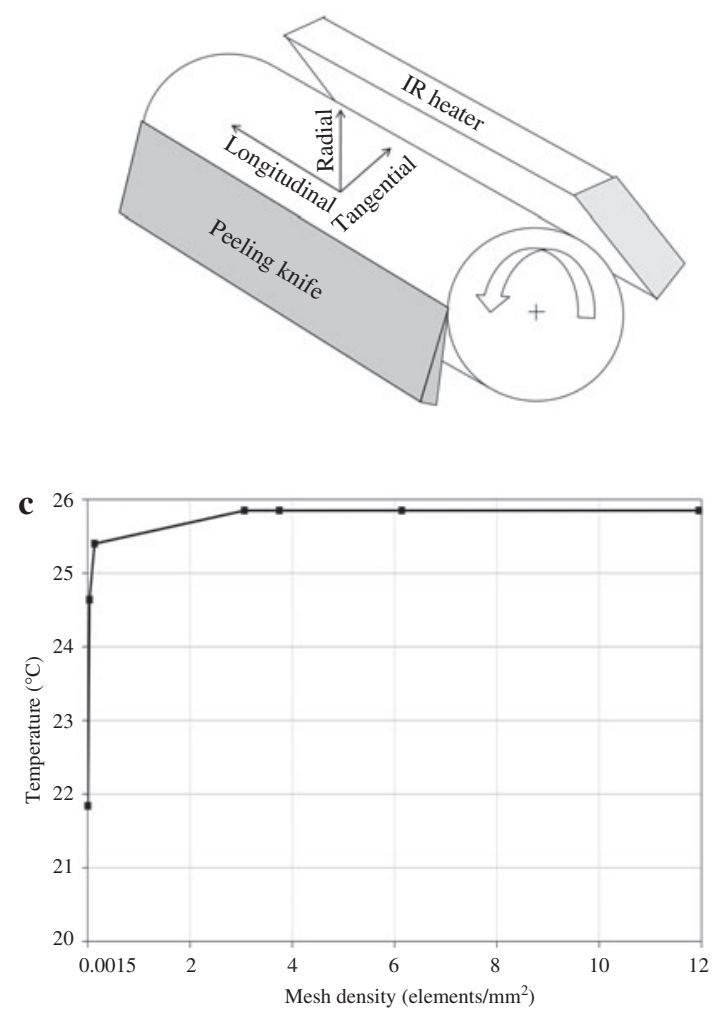

b
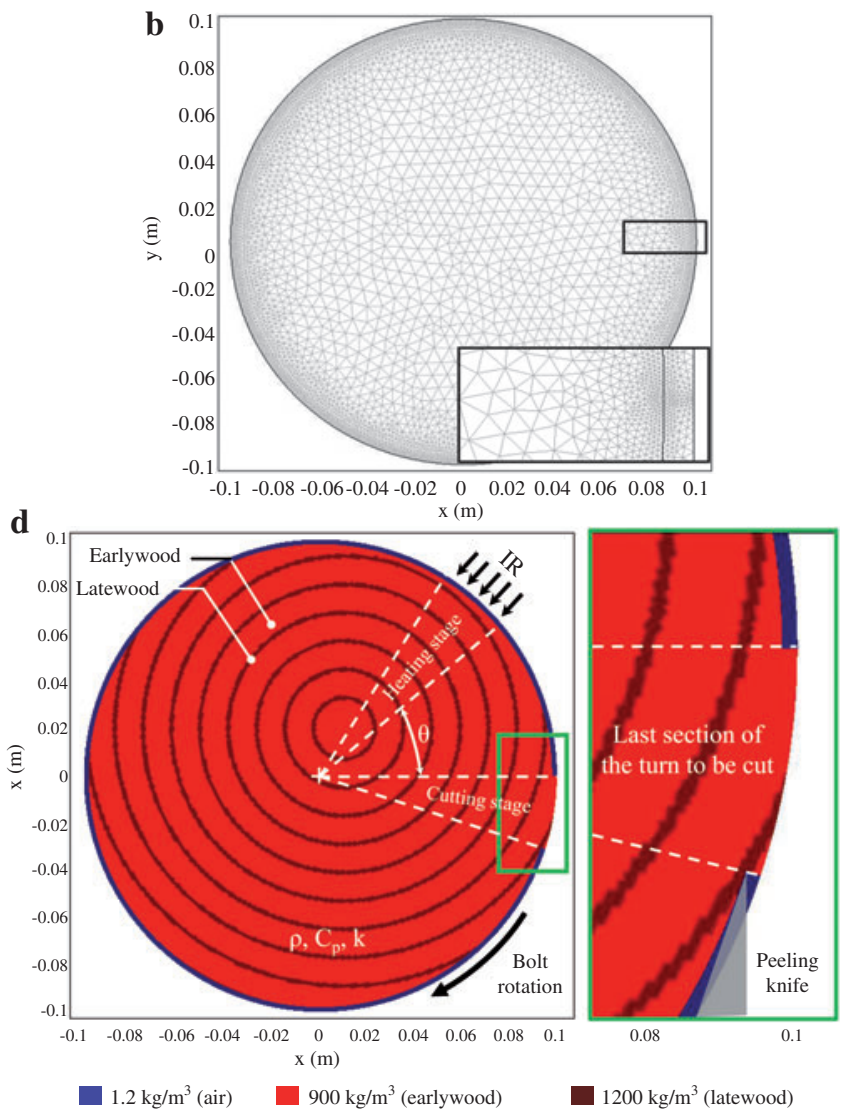

Figure 1 Modeling of IR on-line heating of logs for veneer production. (a) Principle of surface heating, (b) finer mesh close to the bolt surface, (c) influence of mesh-density refinement on results and (d) modeling the surface layer removal, when a peeling of a bolt is defined by subdomain parametric settings (case of off-centered pith) - densities on display.

ability of IR heating to raise the temperature of the surface of a rotating bolt to a certain value, within the shortest possible time (depending on the peeling speed) and to a deepness needed for peeling. On the other hand, overheating should be avoided, which would lead to quality defects on the surface. An open question is, whether sufficient heating of the cutting plane is achievable under industrial peeling conditions. In the industry, peeling speeds, depths and heating temperatures vary as a function of wood species and the end use of the veneers.

In the present study, the following parameters were considered as acceptable under industrial conditions: a minimum temperature of $50^{\circ} \mathrm{C}$ achieved on the cutting plane located up to $3 \mathrm{~mm}$ depth and peeling speeds between 1 to $10 \mathrm{~ms}^{-1}$. The expectation is that modeling the heating of green wood by IR during peeling, will abbreviate the finding of the best process conditions in practice.

\section{Materials and methods}

\section{Methodology}

Software for equation solution: Comsol Multiphysics (Comsol Inc., Burlington, MA, USA), a partial differential equations solver based on the finite element (FE) method, with the overall procedure implemented under the flexible MatLab (MathWorks Inc.,
Natick, MA, USA). This approach offers the following advantages: (1) generating an appropriate and easy-to-modify FE geometry; (2) facilitating the implementation of intrinsic model properties (physical, optical, thermal, structural, etc.) to its geometrical parameters and mesh; and (3) solving partial differential equations with Comsol Multiphysics.

\section{Configuration}

The bolt was modeled in 2D, i.e., the cross-section (radial and transversal directions) whilst the bolt length (the longitudinal direction) can be varied and does not play any role in heat transfer. The IR source was applied locally to the surface of the bolt as depicted in Figure 1(a). The cross-section was meshed by Lagrange-quadratic elements with triangular shapes as the basic functions. To predict heat transfer accurately in the vicinity of the bolt surface, the non-uniform mesh is close to the bolt surface and the cutting plane [Figure 1(b)]. Meshing actually occurs on the whole bolt cross-section, but meshing limited only to the external ring of the bolt up to a sufficient depth might also be considered, if speeding up the calculations is necessary.

A sensitivity analysis indicated that with a minimum element size of $0.7 \mathrm{~mm}$ in the bolt cross-section, a mesh density $>3$ elements per $\mathrm{mm}^{2}$ would be required to obtain a mesh-independent solution. This is illustrated through the evolution of temperature at a point located on the bolt surface according to mesh density [Figure 1(c)]. For mesh density $>3$ elements per $\mathrm{mm}^{2}$, there is no influence of the refinement on the resulting temperatures. 


\section{Equations}

The temperature distribution within the bolt cross-section is governed by the transient heat transfer equation for conduction according to Eq. (1) derived from Fourier's law. This equation only considers IR radiation absorbed by wood surface, and it does not integrate IR penetrated to deeper wood layers (volumetric absorption). The boundary conditions for temperature at the bolt surface are given by Neumann conditions $\left(-\mathbf{n}(-\lambda \nabla \mathrm{T})=\mathrm{Q}_{\mathrm{rad}}\right)$ with $\mathbf{n}$ normal vector to the boundary. Eq. (2) takes into account heat losses due to convection and external input heat due to radiation from the IR source $\mathrm{Q}_{\mathrm{rad}}$ and adiabatic conditions elsewhere:

$\rho C_{p} \frac{\partial T}{\partial t}=\nabla(\lambda \nabla T)$

$\mathrm{Q}_{\mathrm{rad}}=\mathrm{h}\left(\mathrm{T}_{\mathrm{ext}}-\mathrm{T}\right)+\varepsilon \sigma\left(\mathrm{T}_{\mathrm{ext}}^{4}-\mathrm{T}^{4}\right)$

where $\mathrm{C}_{\mathrm{p}}$ is the heat capacity of the wood (in $\mathrm{J} \mathrm{kg}^{-1} \mathrm{~K}^{-1}$ ), $\mathrm{T}_{\text {ext }}$ the external IR source temperature (in $\mathrm{K}$ ), $\mathrm{T}$ is the bolt temperature (in $\mathrm{K}$ ), $\lambda$ the conductivity of wood (in $\mathrm{W} \mathrm{m}^{-1} \mathrm{~K}^{-1}$ ), $\varepsilon$ is the wood emissivity and $\sigma$ is Stefan-Boltzmann's constant (in $\mathrm{W} \mathrm{m}^{-2} \mathrm{~K}^{-4}$ ). The heat transfer coefficient, $\mathrm{h}$, is fixed at $5 \mathrm{~W} \mathrm{~m}^{-2} \mathrm{~K}^{-1}$ (Quéméner et al. 2003). The mean value $\varepsilon=0.85$ is chosen because unplaned wood emissivity is said to vary from 0.70 to 0.98 for temperatures ranging from 17 to $70^{\circ} \mathrm{C}$ (Flir Systems 2004). However, moisture content (MC) is not detailed in these values and the emissivity of green wood would need to be characterized more carefully. Wood emissivity here is independent of the IR wavelength (total emissivity) because the whole emission spectrum of the IR source determined by $\mathrm{T}_{\mathrm{ext}}$ is taken into account (Planck's law).

\section{Subdomain settings}

The cross-section of the bolt is divided into subdomains, with specific initial settings in terms of structural properties - earlywood (EW), latewood (LW) - physical properties (density $\rho$ in $\mathrm{kg} \mathrm{m}^{-3}$ ) and thermal properties $\left(\mathrm{C}_{\mathrm{p}}, \lambda\right)$. All parameters considered to describe the bolt structure, such as bolt diameter, annual ring width, heartwood ring width, latewood ring width, and pith eccentricity, are defined by modifiable input values. Different physical and thermal properties of wood, $\rho, C_{p}$, and $\lambda$, are then applied to the different wood substructures concerning EW and LW and as functions of their MC conditions [Figure 1(d)]. Structural properties such as heartwood/ sapwood, wood rays, and knots have not been taken into account in this model. It is likely that structural properties influence heat transfer into wood, because of their variations in densities and therefore in thermal characteristics. Distinguishing heartwood from sapwood could be integrated in the present mesh, contrary to inserting wood rays and knots, which would necessitate modifying the geometry and the mesh of the model. But given the lack of data concerning their variations in thermal characteristics, definitions of wood structural properties are limited to variations of densities. For this reason, only the influence of MC at $12 \%, 40 \%$, and $72 \%$ on IR heating of green wood is considered in this study. However, thermal properties of wood above the fiber saturation point (FSP) are not available in the literature and are considered as constant at MCs higher than FSP, but a precise characterization of thermal properties of wood above the FSP would be necessary. In all other simulations, MC is set to $72 \%$ (saturated state) with corresponding physical and thermal properties for wood (Table 1).
Table 1 Thermal and physical properties concerning density $(\rho)$, conductivity $(\lambda)$, and heat capacity $\left(C_{p}\right)$ of earlywood (EW) and latewood (LW) as a function of their moisture content (MC) according to Glass and Zelinka (2010) for wood species with specific densities for earlywood of 0.60 and for latewood of 0.70 .

\begin{tabular}{clc}
\hline Parameter & EW & LW \\
\hline$\rho\left(\mathrm{kg} \mathrm{cm}^{-3}\right)$ & 672 & 784 \\
at $12 \% \mathrm{MC}$ & 840 & 980 \\
at $40 \% \mathrm{MC}$ & 1066 & 1204 \\
at $72 \% \mathrm{MC}$ & & \\
$\lambda\left(\mathrm{W} \mathrm{m} \mathrm{K}^{-1}\right)$ & 0.164 & 0.189 \\
at $12 \% \mathrm{MC}$ & 0.196 & 0.226 \\
at $40 \% \mathrm{MC}$ & 0.196 & 0.226 \\
at $72 \% \mathrm{MC}$ & & 3000 \\
$\mathrm{C}_{\mathrm{p}}\left(\mathrm{kJ} \mathrm{kg}^{-1} \mathrm{~K}^{-1}\right)$ & 2000 & 3500 \\
at $12 \% \mathrm{MC}$ & 2700 & 3500 \\
at $40 \% \mathrm{MC}$ & 2700 & \\
at $72 \% \mathrm{MC}$ & & \\
\hline
\end{tabular}

\section{Boundary setting}

The bolt surface is divided into 360 sections with uniform boundary settings. Only the IR source external input $\mathrm{Q}_{\text {rad }}$ (in $\mathrm{Wm}^{-2}$ ) defined with the external IR source temperature $T_{\text {ext }}$ [Eq. (2)] is successively activated with a Boolean operator for each section, with $S_{i}$ of the bolt surface being radiated. $Q_{\mathrm{rad}}$ is applied on a constant number of segments during the whole cutting process. Technical solutions on the peeling lathe are: (1) either the IR source is kept at a constant distance from the bolt and equipped with a deflector able to concentrate radiation with a varying angle on specific bolt segments, or (2) the IR source with a fixed spectrum width adapts its distance to the bolt surface according to the bolt's decreasing radius. The distance between the peeling knife and the IR source is defined by the angle $\theta$ [Figure 1(d)].

\section{Modeling}

For geometric convenience, the real situation was converted by supposing an immobile bolt with an IR heat source turning around it. The relative movement of the IR source and wood to each other is important. On the one hand, the model can simulate only heating of a bolt rotating in front of an IR source without cutting it [Figure 2(a), right path]. In that case, no removal of material is induced and subdomain settings are constant with time. On the other hand, left path in Figure 2(a) simulates IR heating of a rotating bolt while peeling. The continuous removal of a wood surface layer by peeling is modeled by turning the physical properties of each cut segment from wood to air. In Figure $1(\mathrm{~d})$, segments in blue featuring $1.2 \mathrm{~kg} \mathrm{~m}^{-3}$ density represent air, i.e., segments that have been cut from the bolt. In that case, subdomain settings are functions of time and are automatically modified with Boolean functions. At each angular step, each element of the angular section $\mathrm{S}_{\mathrm{i}}$ reaches a new temperature achieved, due to the input of the external IR source and calculated with Eqs. (1) and (2). After each angular step, the IR is moved (by modifying boundary settings) and the last heated section is removed (by turning its density to air density). After each turn, the final calculated temperature of each element is used as the initial temperature of the new meshing element at the bolt surface. In contrast to a real peeling process, where the cutting knife trajectory draws spirals, the model is simplified to the removal of a cylinder of veneer upon every complete rotation. This approximation 

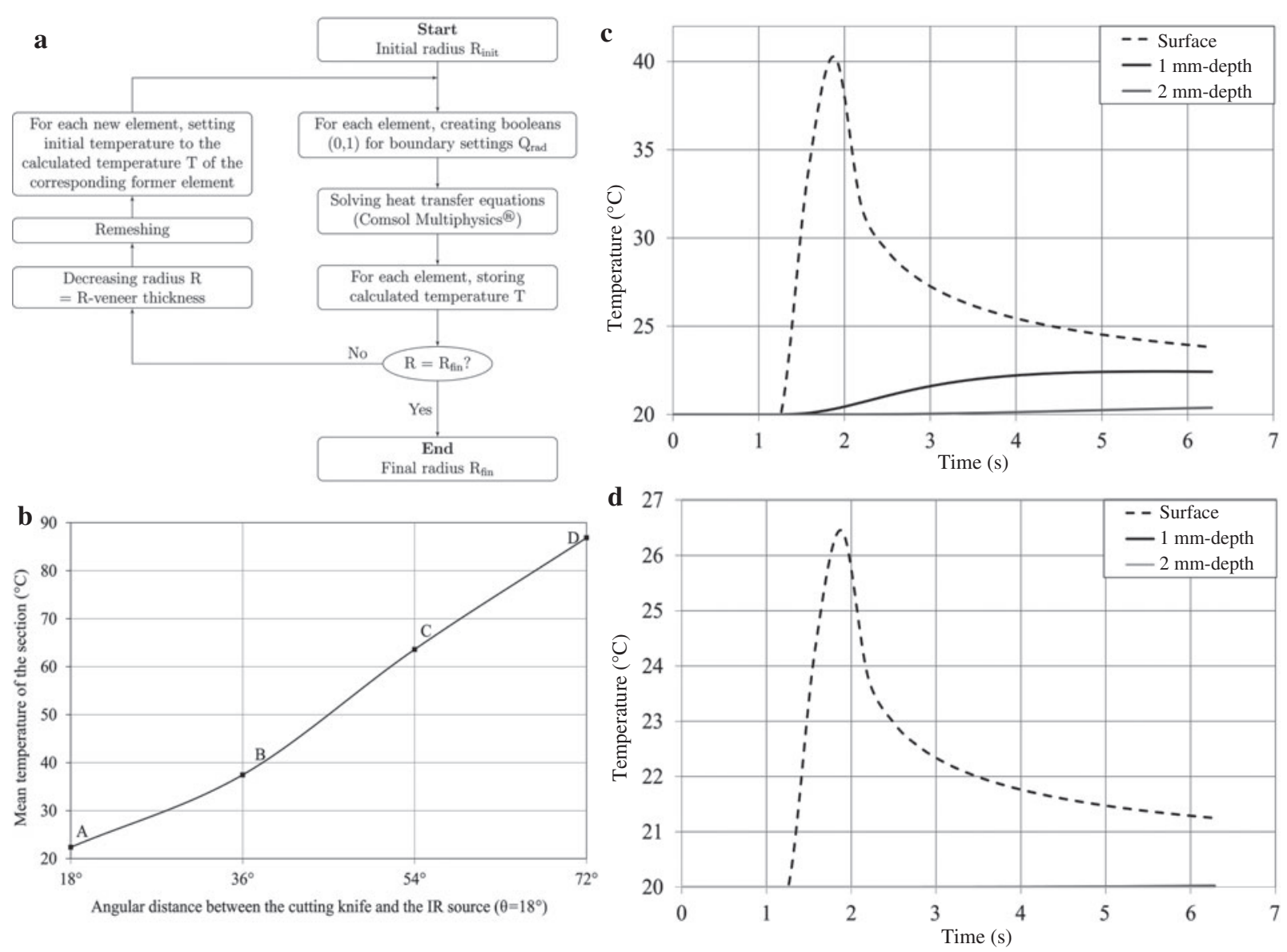

Figure 2 Details of modeling the IR heating during peeling. (a) flow chart of the numerical procedure, (b) influence of the angular distance $\theta$ between knife and IR source $\left(\mathrm{T}_{\text {ext }}=2500^{\circ} \mathrm{C}, \mathrm{v}=0.3 \mathrm{~ms}^{-1}\right.$, bolt diameter $\left.=20 \mathrm{~cm}, \mathrm{MC}=72 \%, \theta=18^{\circ}\right)$, (c) and (d) temporal evolution of temperature within the bolt during one turn of external heating for $\mathrm{T}_{\text {ext }}=500^{\circ} \mathrm{C}$, bolt diameter $=20 \mathrm{~cm}$, and $\mathrm{MC}=72 \%$; however for $(\mathrm{c}) \mathrm{v}=0.1 \mathrm{~ms}^{-1}$ and for (d) $\mathrm{v}=1 \mathrm{~ms}^{-1}$.

only affects the distance between the IR source and the bolt surface to a negligible extent - to that of the veneer thickness - without a significant influence on the numerical simulation of heat transfer.

\section{Results and discussion}

Figures 2(c) and 2(d) show the temporal evolution of temperature during one turn of a rotating bolt initially at $20^{\circ} \mathrm{C}$ and heated by external IR radiation at a source temperature $\mathrm{T}_{\text {ext }}=500^{\circ} \mathrm{C}$ and for cutting speeds of $0.1 \mathrm{~ms}^{-1}$ and $1 \mathrm{~ms}^{-1}$, respectively. The results provide information on the heat transfer behavior deep within the bolt and support 2-step heating kinetics (Bedard and Laganiere 2009). Firstly, the IR energy is absorbed at the wood surface to a negligible penetration depth [dashed curve in Figure 2(c)]. Considering the hypothesis of surface absorption (see Equations), IR heat is then partly lost to the surroundings by convection and partly transferred towards the interior of the bolt by conduction to the deeper layers [black and gray curves in Figure 2(c)]. However, the $2 \mathrm{~mm}$-deep layers never benefit from heat by conduction. This delay in temperature rise corresponds to the time-lapse that must necessarily occur between the heating and cutting stages and can be interpreted geometrically to determine the optimum angular position of the IR source as a function of the bolt diameter. In the present setting [Figure 2(c)], $3 \mathrm{~s}$ are necessary to raise the temperature of a $1 \mathrm{~mm}$ deep layer to the maximum value achievable by conduction of heat from the surface (from $\mathrm{t}=1.5 \mathrm{~s}$ to $\mathrm{t}=4.5 \mathrm{~s}$ ). In the present case, for a cutting speed of $0.1 \mathrm{~ms}^{-1}$ and a bolt of $20 \mathrm{~cm}$ diameter, these $3 \mathrm{~s}$ would be achieved if the IR source is located at an angle of $170^{\circ}$ ahead of the cutting knife.

\section{Distance between knife and IR source}

Figure 2(b) confirms the influence of the angular distance $\theta$ between the cutting knife and the IR source (in the present case, $\theta=18^{\circ}$ ). Clearly, the further the knife is from the IR source, the more time is needed for heat penetration into the bolt, and therefore, the higher must be the temperature. Temperatures in Figure 2(b) are mean values within each segment $\mathrm{A}, \mathrm{B}, \mathrm{C}$, and $\mathrm{D}$ for source temperature $\mathrm{T}_{\mathrm{ext}}=2500^{\circ} \mathrm{C}$ and peeling speed $\mathrm{v}=0.3 \mathrm{~ms}^{-1}$. 


\section{Peeling speeds and source temperatures}

Varying peeling speeds $\left(0.1,0.5\right.$, and $\left.1 \mathrm{~ms}^{-1}\right)$ and source temperatures $\left(500,1500\right.$, and $\left.2500^{\circ} \mathrm{C}\right)$ lead to the same 2-step heat transfer behavior as shown in Figures 2(c) and 2(d) [Figures 3(a) and 3(b)]. The high amount of energy absorbed at the bolt surface is transferred by conduction to the adjacent layers beneath. Logically, heating rates decrease with higher peeling speed, thicker veneer thickness and lower IR source temperature [Figures 2(c), 2(d), 3(a) and 3(b)]. Approaching industrial peeling speeds at around $1 \mathrm{~ms}^{-1}$, the time is too short to enable heat transfer by conduction from the surface to deeper layers. For peeling speeds above $0.5 \mathrm{~ms}^{-1}$, the temperature rise in the $2 \mathrm{~mm}$-deep layer becomes effectively insignificant as shown in Figure $3 \mathrm{~b}$. Increasing the source temperature from 500 to $2500^{\circ} \mathrm{C}$ does not improve this situation; it only leads to the risk of the bolt surface burning with the maximum of curves reaching temperatures above $300^{\circ} \mathrm{C}$.

\section{Rotation without cutting}

For the above-mentioned reasons, a possibility was investigated, in which the bolt was left turning in front of the IR source before cutting starts. This would allow more time for heat transfer into deeper layers. Figures $3 a$ and $3 b$ illustrate the temperature evolution within the bolt as a function of the number of rotations for peeling speeds of $0.1,0.5,1 \mathrm{~ms}^{-1}$ and source temperature $\mathrm{T}_{\text {ext }}=500^{\circ} \mathrm{C}$. At depths of $1 \mathrm{~mm}$ [Figure 3(a)] and $2 \mathrm{~mm}$ [Figure 3(b)], the temperature rise is perceptible.

Figure 3(c) illustrates this situation (continuous curve) before cutting starts on the 6th turn (dashed curve). The temperature evolution as a function of the number of turns is given for a "floating" layer always located at $2 \mathrm{~mm}$ deep from the cutting plane, therefore, at varying bolt diameters detailed in the data labels. These simulations provide information about the temperatures achievable at the cutting plane, where cutting is interrupted by heating stages. This solution could only be considered for slicing (non-continuous cutting process) but not for the continuous peeling process. However, the configuration of the heating system should be optimized to adapt it to realistic slicing speeds (approx. $1 \mathrm{~ms}^{-1}$ ) with heating source temperatures, which would not lead to burning of the surface.

\section{Influence of MC}

Figure 3(d) illustrates the influence of MC on temperature elevation at local points of the bolt surface, for a source temperature of $2500^{\circ} \mathrm{C}$. Firstly, for the same amount of energy from the IR source, the final temperature reached at the bolt surface
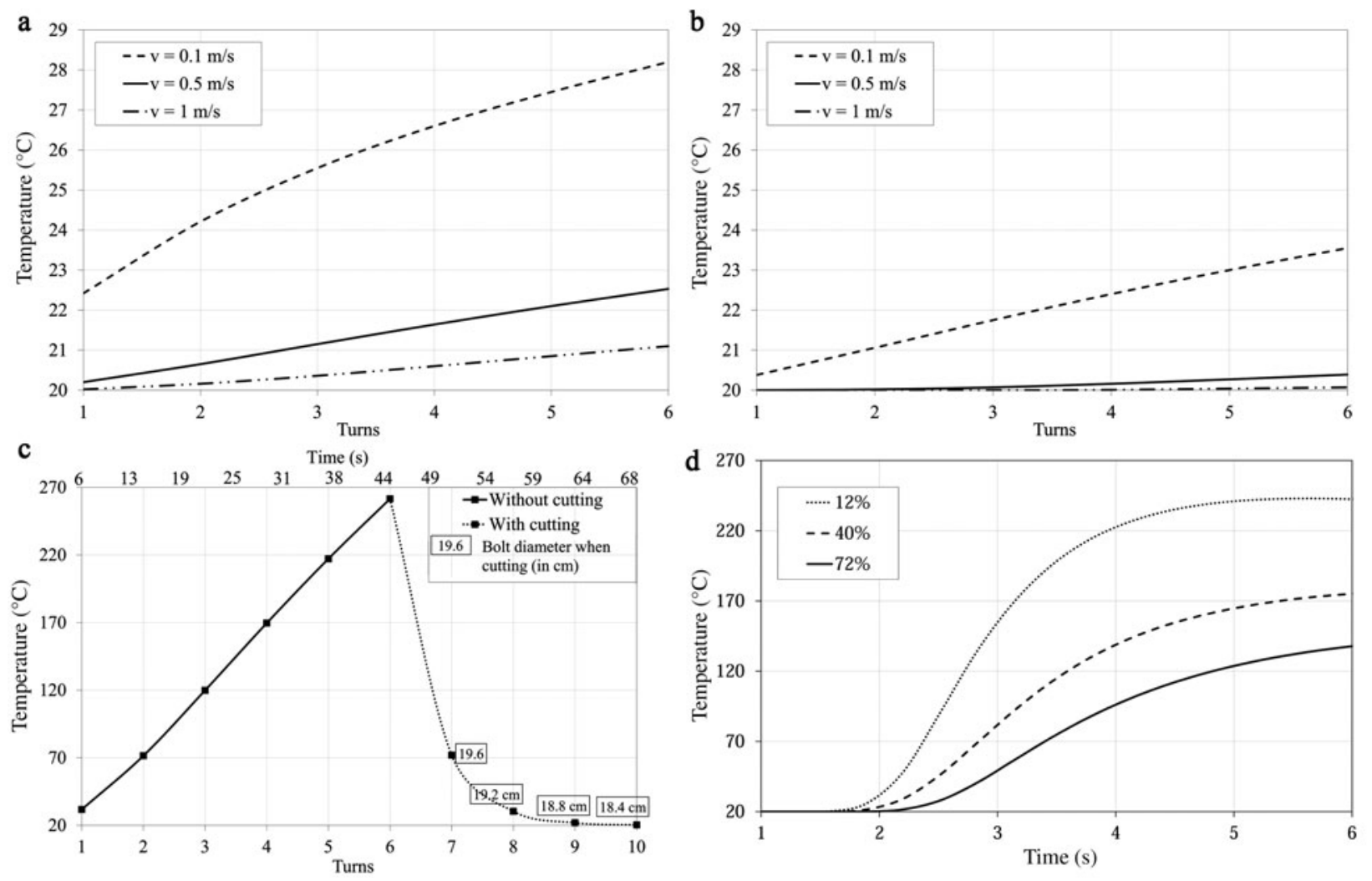

Figure 3 Temperature evolution as a function of turn number for bolts with $20 \mathrm{~cm}$ diameter. (a) $\mathrm{T}_{\text {ext }}=500^{\circ} \mathrm{C}$, e $=1 \mathrm{~mm}$, variable cutting speeds, (b) $\mathrm{T}_{\text {ext }}=500^{\circ} \mathrm{C}, \mathrm{e}=2 \mathrm{~mm}$, variable cutting speeds, (c) constant $2 \mathrm{~mm}$ depth, $\mathrm{T}_{\text {ext }}=2500^{\circ} \mathrm{C}, \mathrm{v}=0.1 \mathrm{~ms}^{-1}$, (d) temperature elevation at the bolt surface as a function of $\mathrm{MC}$ and time, if $\mathrm{T}_{\mathrm{ext}}=2500^{\circ} \mathrm{C}, \mathrm{v}=0.1 \mathrm{~ms}^{-1}$. 
is lower when the MC is higher. Then, the time required to reach the maximum surface temperature is longer when the $\mathrm{MC}$ is higher. Figure 3(d) illustrates that the influence of MC on wood heating can be predicted by means of parametric definitions of the physical properties of wood. Given the significant influence of $\mathrm{MC}$, it might be of interest, in the future, to integrate mass transfer equations in the model to take into account the effect of drying during heating. Although the presented model does not take into account the heterogeneity of wood, it clearly shows the roles that various parameters play in influencing heat transfer. It is particularly the case concerning the influence of MC on wood heat transfer.

\section{Conclusions}

The simulation provides information on the optimum configuration of the IR heating system, to achieve the temperatures required on the cutting plane. Firstly, to ensure heat penetration up to the cutting plane, it is necessary to let the bolt turn in front of the IR source before cutting starts. The model enables calculation of the number of turns before cutting commences, according to the peeling settings. Then, the position of the IR source can be geometrically determined as a function of the time calculated by the model for heat transfer from the bolt surface to adjacent layers. Given the significant losses due to convection to the exterior environment and the relatively slow conduction process, the IR source should be located as far as possible from the knife. The presented model could be a part of an essential decision-making tool, prior to the design of in-line IR heating system directly embedded on the cutting machine. The results support the utilization of IR heating for slicing processes. Experimental data are needed for validating the presented calculations. The flexibility of this model permits the modification of input parameters, if necessary, in the course of matching data of simulation and experiments. In the future, the model should integrate the thermal properties of wood $\left(\mathrm{C}_{\mathrm{p}}, \lambda\right)$ also above the fiber saturation point. Moreover, the optical properties of green wood in terms of emissivity, transmissivity, and absorptivity must be taken into account for situations when IR should penetrate into deeper layers. Last but not least, the presence of wood radial elements, such as knots and rays, whose high densities play a significant role in heat transfer, must be included into future models.

\section{References}

Baldwin, R.F. (1975) Plywood Manufacturing Practices. Miller Freeman Publications Inc., San Fransisco, California, pp. 62-78.

Bardet, S., Beauchêne, J., Thibaut, B. (2003) Influence of basic density and temperature on mechanical properties perpendicular to grain of ten wood tropical species. Ann. Forest Sci. 60:49-59.

Bedard, N., Laganiere, B. (2009) Debarking enhancement of frozen logs. Part II: infrared system for heating logs prior to debarking. Forest Prod. J. 59:25-30.

Buchelt, B., Pfriem, A. (2011) Influence of wood specimen thickness on its mechanical properties by tensile testing: solid wood versus veneer. Holzforschung 65:249-252.
Coste, N. (2005) Interest of radiant energy for wood peeling and slicing process. Master's thesis, University of Melbourne.

Dupleix, A., Marchal, R., Bléron, L., Rossi, F., Hughes, M. (2011) On-line heating temperatures of green-wood prior to peeling. Joint International Symposium on Wood Composites and Veneer Processing and Products Proceedings.

Flir Systems (2004) ThermaCAM User's Manual.

Gaudilliere, C. (2003) Contribution au développement d'une chauffe électrique rapide de bois vert de Douglas en vue de son déroulage. Master's thesis, Arts et Métiers ParisTech.

Glass, S.V., Zelinka, S.L. (2010) Wood handbook, Chapter 03: Moisture relations and physical properties of wood. General Technical Report FPL-GTR-190 Department of Agriculture, Forest Service, Forest Products Laboratory, Madison, WI, USA. 3-1-3-19.

Klüppel, A., Mai, C. (2012) Effect of lignin and hemicelluloses on the tensile strength of micro-veneers determined at finite span and zero span. Holzforschung 66:493-496.

Lutz, J.F. (1960) Heating veneer bolts to improve quality of douglas-fir plywood. Technical report USDA Forest Service General FPL-2182, Forest Products Laboratory, Madison, WI, USA.

Marchal, R., Collet, R. (2000) Contribution au développement d'une chauffe électrique rapide de bois vert de douglas en vue de son déroulage. Technical report, Arts et Métiers ParisTech.

Marchal, R., Gaudilliere, C., Collet, R. (2004) Technical feasibility of an embedded wood heating device on the slicer or the peeling lathe. International Symposium Veneer Processing and Products Proceedings. pp. 29-44.

Marchal, R., Mothe, F., Denaud, L.-E., Thibaut, B., Bleron, L. (2009) Cutting forces in wood machining - Basics and applications in industrial processes. A review COST Action E35 2004-2008: Wood machining - micromechanics and fracture. Holzforschung 63:157-167.

Matsunaga, M., Minato, K. (1998) Physical and mechanical properties required for violin bow materials II: Comparison of the processing properties and durability between pernambuco and substitutable wood species. J. Wood Sci. 44:142-146.

Potter, B.E., Andresen, J.A. (2010) A finite-difference model of temperatures and heat flow within a tree stem. Revue Canadienne de Recherche Forestière 32:548-555.

Quéméner, O., Battaglia, J.L., Neveu, A. (2003) Résolution d'un problème inverse par utilisation d'un modèle réduit modal. Application au frottement d'un pion sur un disque en rotation. Int. J. Thermal Sci. 42:361-378.

Sinn, G., Sandak, J., Ramananantoandro, T. (2009) Properties of wood surfaces - characterisation and measurement. A review COST Action E35 2004-2008: Wood machining - micromechanics and fracture. Holzforschung 63:196-203.

Srinivasan, N., Bhattacharyya, D., Jayaraman, K. (2007) Thermoforming of wood veneer composite sheets. Holzforschung 61:558-562.

Stanzl-Tschegg, S., Navi, P. (2009) Fracture behaviour of wood and its composites. A review COST Action E35 2004-2008: Wood machining - micromechanics and fracture. Holzforschung 63:139-149.

Torgovnikov, G., Vinden, P. (2010) Microwave wood modification technology and its applications. Forest Prod. J. 60:173.

Yamauchi, S., Iijima, Y., Doi, S. (2005) Spectrochemical characterization by FT-Raman spectroscopy of wood heat-treated at low temperatures: Japanese larch and beech. J. Wood Sci. 51:498-506. 